\title{
EXPERIMENTAL DETERMINATION OF SELECTED LOADING RESISTANCE FORCES OF A SINGLE BUCKET LOADER
}

\author{
D. Stefanow*
}

\begin{abstract}
Experimental determination of each component of loading resistance force occurring in different parts of the bucket is very difficult. In the article, measurements of total loading resistance force during the initial loading phase are presented. Based on a semi-empirical model available in the literature, the author was able to estimate values of each component of loading resistance in the first loading phase, based on measured traction forces. Based on the results, experimental coefficients of soil cutting resistance were obtained. These values can be valuable during optimization of the loading process, such as predicting the optimal trajectories of the bucket for various loaded materials.
\end{abstract}

Keywords: loading, wheel loader, energy efficiency

\section{Introduction}

Similarly as in case of other earth-moving processes, loading is a very energy consuming process. It is therefore often subject to optimization in order to increase the energy efficiency of the process (Skurjat, 2014). Other common trend is automation of the earth-moving process (Kosiara et al., 2016, Chołodowski, 2016). However, automation of loading itself, requires the knowledge of certain phenomena occurring during the soil-tool interaction, which is in fact rarely investigated. In the Department of Off-Road Machine and Vehicle Engineering (DORMVE), research in this field has been conducted for many years (Dudziński et al., 1996). Benefiting from these experiences, a new test rig has been designed for investigation of the loading process in a wide range of parameters of the soil, machine and the process (Czabanowski et al., 2016). The goal of this paper was to determine what are the resistance forces that act on a bucket during the initial phase of material loading (i.e. when the manipulator is not being lifted, only the whole vehicle is driven). In order to do so, tests have been carried out on the test rig, with a bucket penetrating a pile of breakstone. Based on that and a semi-empirical model available in the literature, values of selected resistance force components have been calculated.

\section{Experimental setup}

The test rig consists of a few basic components and is depicted in the Fig.1a.:

- Wheel miniloader Avant 218

- Special measurement platform with 4 measuring segments equipped with a set of sensors in order to measure reaction forces in normal and longitudinal directions under each loader wheel.

- A semi-open soil bin which allows to form the soil pile with appropriate height and inclination. 


\section{Determination of forces acting on the bucket}

In this study, a semi-empirical method of determination of loading resistance presented by Pieczonka (2007) was applied. The method assumes that the resultant loading resistance force during the initial phase equals:

$$
F=F_{1}+2 F_{2}+F_{3}+4 F_{4}+F_{5}+F_{6}
$$

Where:

- $F_{1}$ - Force on the cutting edge and teeth,

- $F_{2}$ - Force on the edges of sidewalls,

- $\quad F_{3}$ - Friction force between material inside the bucket and the bottom wall,

- $F_{4}$ - Friction force between the material and sidewall sides (inner and outer),

- $\quad F_{5}$ - Friction force between the bottom wall and material under it or the ground,

- $F_{6}$ - Force resulting from passive material pressure acting on back wall of the bucket.

A diagram of forces acting on the tool is shown in the Fig. $1 b$.

a)

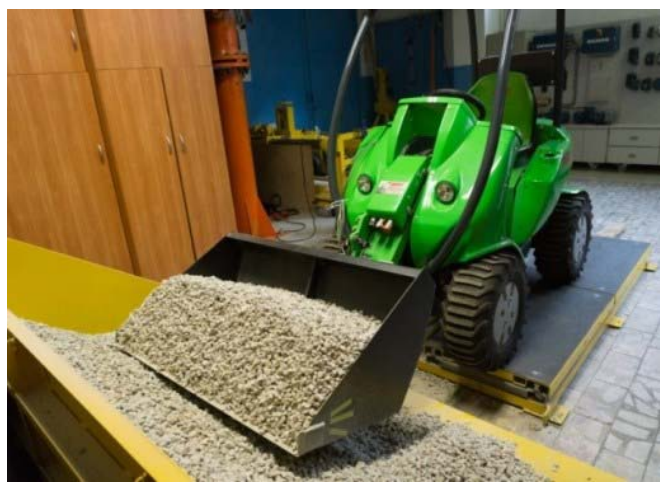

b)

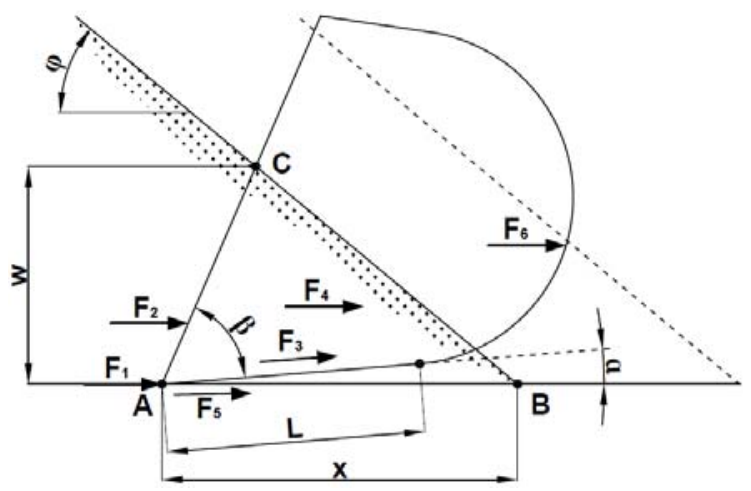

Fig. 1: a) Experimental setup in the laboratory of DORMVE; b) Diagram of forces acting on a bucket

Below, a set of equations that are required to be solved in order to determine each component of resistance force has been presented. According to the model, resultant resistance force consists of 6 components. As the goal of the study was to determine resistance forces during the initial phase of loading, force on the back wall of the bucket $\left(\mathrm{F}_{6}\right)$ did not have to be taken into consideration. Measurements were taken only up to penetration length $x=L$, i.e. the length of the bottom wall. During the measurements, the bottom bucket wall was oriented horizontally $\left(\alpha=0^{\circ}\right)$ and suspended $50 \mathrm{~mm}$ above the ground. Considering these factors, resistance force generated between the bottom bucket wall and the ground $\mathrm{F}_{5}$ can be also neglected. Therefore, the total resistance force considered, consists of 4 components:

$$
F^{\prime}=F_{1}+2 F_{2}+F_{3}+4 F_{4}
$$

For solving the following equations, parameters listed in Tab. 1 were used. These are actual parameters of the bucket and the soil pile.

According to Pieczonka (2007) and Fig. 1b, the following equations determine each component of resistance force. Precise forumlation of the model can be found in the book by Pieczonka (2007). Below are presented only the outlines: 
Tab. 1: Parameters of the experimental setup used in the calculation.

\begin{tabular}{ccc}
\hline Parameter & Symbol & Value \\
\hline Bucket width & $\mathrm{B}$ & $0,95[\mathrm{~m}]$ \\
\hline Length of the bottom wall of the bucket & $\mathrm{L}$ & $0,4[\mathrm{~m}]$ \\
\hline Bucket angle & $\beta$ & $45\left[^{\circ}\right]$ \\
\hline Material pile angle & $\varphi$ & $25\left[^{\circ}\right]$ \\
\hline Orientation of the bottom wall of the bucket & $\alpha$ & $0\left[^{\circ}\right]$ \\
\hline Material bulk density & $\rho$ & $1800\left[\mathrm{~kg} / \mathrm{m}^{3}\right]$ \\
\hline Steel-soil interface friction & $\mu_{\mathrm{z}}$ & $0,4[-]$ \\
\hline Tool tip wear factor & $\mathrm{k}_{\mathrm{z}}$ & $1[-]$ \\
\hline
\end{tabular}

$$
\begin{gathered}
F_{1}=k_{x} B x^{n} k_{z} \\
F_{2}=\frac{1}{1+n} k_{x} w B x^{n} k_{z} \\
w=\frac{x \tan \varphi \tan \beta}{\tan \varphi+\tan \beta}
\end{gathered}
$$

where: $\mathrm{w}$ - height of the tool interacting with soil

$\mathrm{k}_{\mathrm{x}}$-cutting resistance coefficient of the cutting edges obtained experimentally $\left[\mathrm{N} / \mathrm{m} / \mathrm{m}^{\mathrm{n}}\right]$,

$\mathrm{n}$ - power factor dependent on soil grain size and density obtained experimentally $\left[\mathrm{kg} / \mathrm{m}^{3}\right]$,

$\mathrm{x}$ - tool tip horizontal penetration depth [m].

$$
F_{3}=\mu_{z} \int_{A} \sigma_{z} d A
$$

where: $\sigma_{z}-$ pile pressure on lower wall $\left[\mathrm{N} / \mathrm{m}^{2}\right]$,

A - contact surface $\left[\mathrm{m}^{2}\right]$.

$$
\sigma_{z}=x \rho g \cdot \tan \varphi\left(1+\sin ^{2} \varphi\right)
$$

Therefore:

$$
\begin{gathered}
F_{3}=\frac{1}{2} \mu_{z} \rho g B \cdot \tan \varphi\left(1+\sin ^{2} \varphi\right) x^{2} \\
F_{4}=\mu_{z} \int_{A_{s}} \sigma_{s} d A_{s}
\end{gathered}
$$

where: $\sigma_{\mathrm{s}}-$ soil pressure on side wall $\left[\mathrm{N} / \mathrm{m}^{2}\right]$,

A - contact surface $\left[\mathrm{m}^{2}\right]$.

$$
\begin{gathered}
\sigma_{s}=x \rho g \cdot \tan \varphi\left(1+\sin ^{2} \varphi\right) \cdot \tan ^{2}\left(\frac{\pi}{4}-\frac{\varphi}{2}\right) \\
A_{A B C}=\frac{1}{2} x w
\end{gathered}
$$

Therefore:

$$
F_{4}=\frac{\mu_{z} \rho g \cdot \tan \beta \cdot \tan ^{2} \varphi\left(1+\sin ^{2} \varphi\right) \cdot \tan ^{2}\left(\frac{\pi}{4}-\frac{\varphi}{2}\right)}{6(\tan \varphi+\tan \beta)} x^{3}
$$

In the Fig. 2 results of experimental tests of six measurements and line representing the force $\mathrm{F}^{6}$ calculated using the model are presented. Applying formulas 2-12 it was possible to estimate values of each resistance force component $\mathrm{F}_{1-4}$, which are presented in the Fig. $2 \mathrm{a}$. 


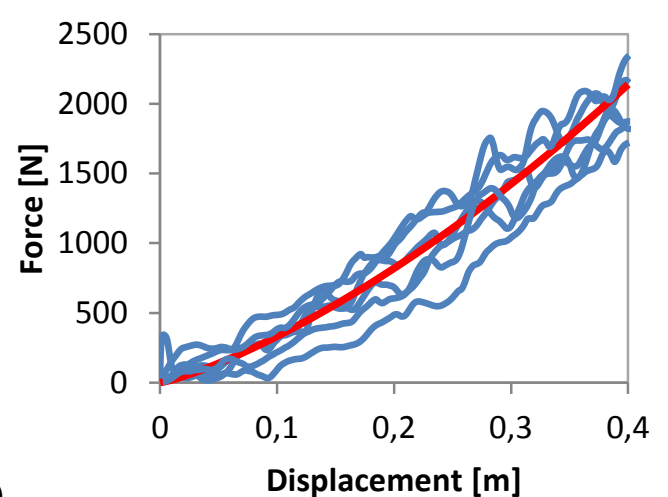

a)

Fig. 2: a) Measured forces and calculated total resistance force $F^{\prime}$; b) Estimated values of resistance forces acting on the bucket for $k_{x}=5055[\mathrm{~N} / \mathrm{m} / \mathrm{mn}]$ and $n=1,198$

Applying the model (2), using the least square method, a regression function (represented by line F' in the Fig. 2b) was determined. It has two constants, $\mathrm{k}_{\mathrm{x}}$ and $\mathrm{n}$, which have been presented in Tab. 1 .

Tab. 2: Parameters determined in the study

\begin{tabular}{lcc}
\hline \multicolumn{1}{c}{ Parameter } & Symbol & Determined value \\
\hline Factor dependent on grain size and density of soil & $\mathrm{n}$ & $1,198[-]$ \\
\hline Coefficient of soil cutting resistance at the bucket edge & $\mathrm{k}_{\mathrm{x}}$ & $5055\left[\mathrm{~N} / \mathrm{m} / \mathrm{m}^{\mathrm{n}}\right]$ \\
\hline
\end{tabular}

\section{Conclusion}

Experimental determination of each component of resistance force acting on the bucket separately is almost impossible. Thanks to a semi-empirical model proposed by Pieczonka (2007) the author was able to estimate the values of each resistance force during the initial loading phase. Estimation was based on experiment held on a special test rig, that allows recording the resultant resistance and displacement of the bucket. The measured resultant force from 6 measurements was approximated by a progressive line representing model (2). Based on it, values of two constants, $\mathrm{k}_{\mathrm{x}}$ and $\mathrm{n}$, of the model were determined. Having these parameters, it is possible to estimate values of each component of resistance force. One has to remember, that these two parameters reflect only conditions assumed in this study, however it shows the method can be a helpful tool in optimization of the loading process. More work is planned to be done in order to determine resistance forces acting on the bucket during the whole loading process, which is in fact crucial for effective optimization.

\section{References}

Chłodowski, J. (2016) Assessment of applicability of Inertial Measurement Units (IMU) in contactless measurements of orientation of main bodies of work machines, Interdisciplinary Journal of Engineering Sciences, Vol. IV, No. 1, pp. 24-27.

Czabanowski, R., Leśniak, Ł. and Łabuda, A. (2016) Computer measurement system of the laboratory stand for testing the loading proces of bucket loader, Autobusy, 12/2016, pp. 888-891.

Dudziński, P., Pieczonka, K. and Wysłuch, Z. (1996) Automatic systems for steering and controlling bucket loaders, searching for solutions. Proc. 1st Int. Conf. Off-Road Machines and Vehicles in Theory and Practice, Wrocław.

Kosiara, A. and Sumara, A. (2017) An operator assistance vision system for adjustment of excavator body orientation with respect to the ground, Autobusy, 12/2017, pp. 978-982.

Pieczonka, K. (2007) Off-road machine engineering. Wrocław University of Science and Technology Press, Wrocław.

Skurjat A. (2014) Investigation of energy efficiency of a wheel loader manipulator during a work cycle, Transport Przemysłowy i Maszyny Robocze, No 1, pp. 65-69 